\title{
Intraoperative neurophysiological mapping and monitoring in spinal tumor surgery: sirens or indispensable tools?
}

\author{
Antonino Scibilia, MD, ${ }^{1}$ Carmen Terranova, MD, ${ }^{2}$ Vincenzo Rizzo, MD, PhD, ${ }^{2}$ Giovanni Raffa, MD, \\ Adolfo Morelli, BS, ${ }^{2}$ Felice Esposito, MD, PhD, ${ }^{1}$ Raffaella Mallamace, MD, ${ }^{3}$ Gaetano Buda, MD, ${ }^{3}$ \\ Alfredo Conti, MD, PhD, ${ }^{1}$ Angelo Quartarone, MD, ${ }^{2}$ and Antonino Germanò, MD1
}

\begin{abstract}
Divisions of ${ }^{1}$ Neurosurgery, ${ }^{2}$ Neurology, and ${ }^{3}$ Anesthesiology; and ${ }^{4}$ Department of Clinical and Experimental Medicine, University of Messina, Italy
\end{abstract}

Spinal tumor (ST) surgery carries the risk of new neurological deficits in the postoperative period. Intraoperative neurophysiological monitoring and mapping (IONM) represents an effective method of identifying and monitoring in real time the functional integrity of both the spinal cord (SC) and the nerve roots (NRs). Despite consensus favoring the use of IONM in ST surgery, in this era of evidence-based medicine, there is still a need to demonstrate the effective role of IONM in ST surgery in achieving an oncological cure, optimizing patient safety, and considering medicolegal aspects. Thus, neurosurgeons are asked to establish which techniques are considered indispensable. In the present study, the authors focused on the rationale for and the accuracy (sensitivity, specificity, and positive and negative predictive values) of IONM in ST surgery in light of more recent evidence in the literature, with specific emphasis on the role of IONM in reducing the incidence of postoperative neurological deficits. This review confirms the role of IONM as a useful tool in the workup for ST surgery. Individual monitoring and mapping techniques are clearly not sufficient to account for the complex function of the SC and NRs. Conversely, multimodal IONM is highly sensitive and specific for anticipating neurological injury during ST surgery and represents an important tool for preserving neuronal structures and achieving an optimal postoperative functional outcome.

http://thejns.org/doi/abs/10.3171/2016.5.FOCUS16141

KEY WORDS D wave; electromyography; intraoperative monitoring; motor evoked potential; spinal tumor surgery; somatosensory evoked potential

$\mathrm{D}$ ESPITE recent advances in the neurosurgical strategies adopted for the treatment of spinal tumors (STs), the surgery still bears the significant risk of causing intraoperative damage, with morbidity ranging from $3.7 \%$ to $7.5 \% .^{16}$ The neurosurgical goal is to achieve a maximal safe resection, a compromise between the best oncological result and the preservation of neurological function. For this, intraoperative neurophysiological monitoring and mapping (IONM) represents the most effective technique for identifying and monitoring in real time the functional integrity of both the spinal cord (SC) and the nerve roots (NRs). And although there is increasing evidence and consensus among experts that IONM is valuable in spine surgery ${ }^{43}$ and level A recommendations have been published regarding the fact that surgeons and other members of the operating team should be alerted to the increased risk of severe adverse neurological outcomes in patients with significant IONM changes, ${ }^{36}$ no studies in humans have directly measured the efficacy of operative and/or anesthetic interventions in these cases. Moreover, to prevent rather than merely predict the occurrence of a postoperative neurological injury, the team needs a long educational period with expert-based training to be able to discriminate between alerts (false positive and false negative); a specifically IONM-oriented operating theater setup; and mutual collaboration in wiring, screwing, taping, monitoring, vein and artery cannulating, cuffing, and even positioning the patients and the IONM tools.

ABBREVIATIONS BCR = bulbocavernosus reflex; CST = corticospinal tract; $\mathrm{D}$ wave = direct wave; $\mathrm{DCM}=$ dorsal column mapping; $\mathrm{DNS}=$ direct nerve stimulation; EXDST = extradural spinal tumor; frEMG = free-running electromyography; IDEMSCT = intradural-extramedullary SC tumor; IMSCT = intramedullary spinal cord tumor; IONM = intraoperative neurophysiological monitoring and mapping; MEP = motor evoked potential; $\mathrm{mIONM}=$ multimodal IONM; $\mathrm{mMEP}=$ muscle MEP; $\mathrm{NPV}=$ negative predictive value; $\mathrm{NR}=$ nerve root; $\mathrm{PPV}=$ positive predictive value; $\mathrm{SC}=$ spinal cord; $\mathrm{SSEP}=$ somatosensory evoked potential; $\mathrm{ST}=$ spinal tumor.

SUBMITTED April 1, 2016. ACCEPTED May 26, 2016.

INCLUDE WHEN CITING DOI: 10.3171/2016.5.FOCUS16141. 


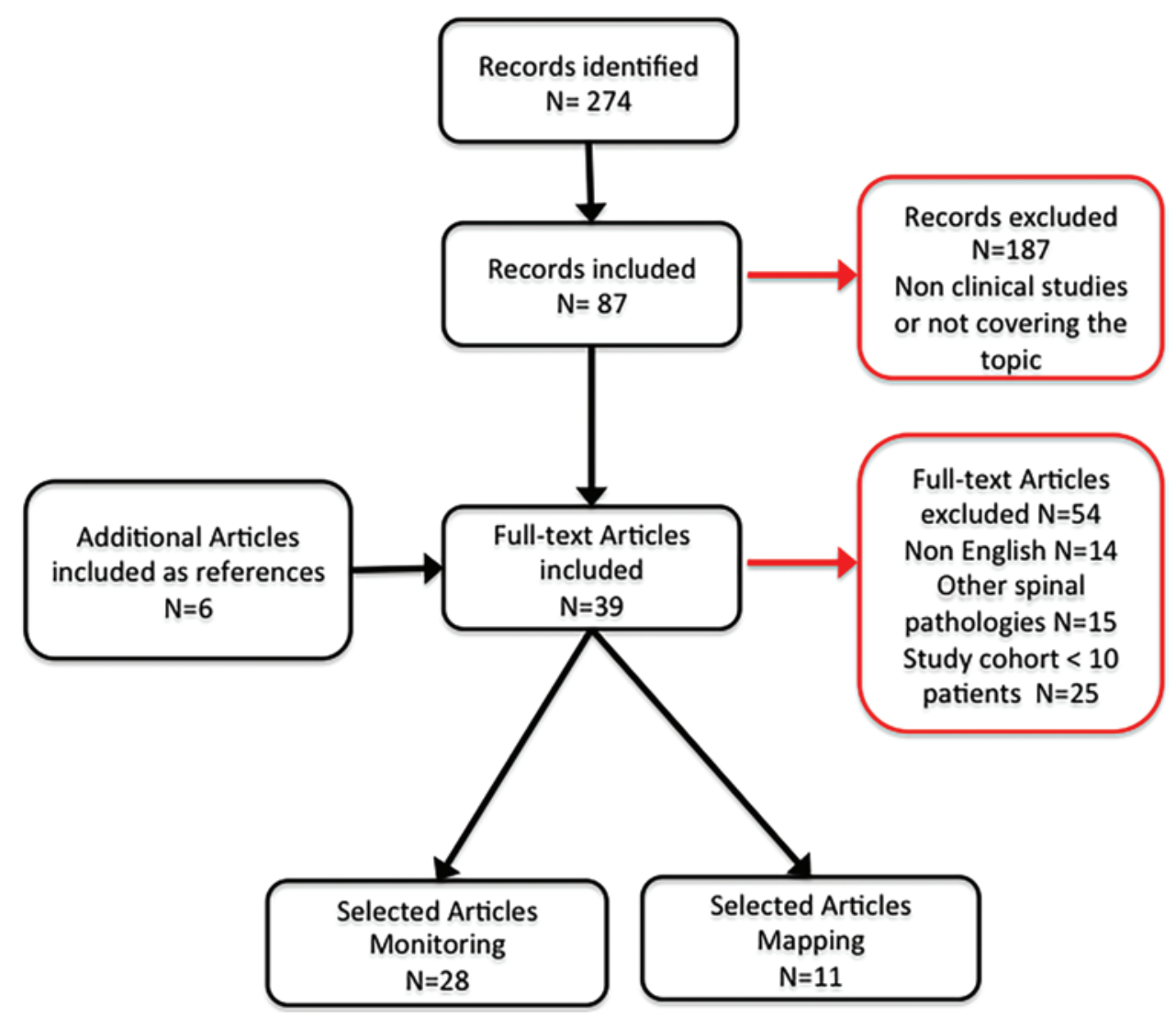

FIG. 1. Flow diagram of the selection process to identify studies for review.

In this era of evidence-based medicine, there is still a need to demonstrate the effective role of IONM in ST surgery to improve patient safety and outcomes and to reduce malpractice issues. We are asked to prove that monitoring "really makes a difference" and to establish which tools are sirens and which are indispensable tools. Our aim in this study was to address the rationale for and the accuracy (in terms of sensitivity and specificity, positive and negative predictive value) of IONM in light of more recent evidence in the literature, with specific emphasis on evaluating the role of IONM in reducing the incidence of postoperative neurological injury and mitigating its severity.

\section{Methods}

We performed a literature search of the Medline, Embase, and Ovid (latest access March 30, 2016) databases using the key words "intraoperative," "monitoring," and "spinal tumor," highlighting papers addressing the accuracy and validation of individual IONM techniques, each technique's prognostic significance, and its role as a single tool and in a multimodal integrated setup. We focused on papers dealing with STs. In the literature, 2 main strategies for IONM during spinal surgery have been described for assisting in the diagnosis of neurological injury. Basically, the monitoring techniques allow for functional assessment of neuronal integrity and the mitigation of injury severity, while mapping serves to identify the anatomical and functional locations of the SC and NRs. To make ap- propriate selections from among the identified papers, we considered a minimum cohort size to be 10 patients for the inclusion of articles dealing with monitoring techniques; however, no limitations on cohort size were used as a criterion for including articles dealing exclusively with mapping procedures because of the limited number of pertinent studies. Exclusion criteria were non-English language articles, articles dealing with IONM of diseases other than STs, and series published in the pre-microneurosurgical era. Records were identified and independently reviewed by 2 physicians (A.S. and G.R.). Additional articles found among the cited references in the reviewed studies were included as well.

\section{Results}

The literature search identified an initial set of 274 reports. Figure 1 features a flow diagram of the selection process for identifying studies for review. We excluded 187 records because they did not cover the topic of this study or they were nonclinical studies. The full text of the remaining 87 articles was reviewed, and 33 met our selection criteria. Fifty-four papers were excluded because they were written in a language other than English (14 articles), they were focused on other spinal pathologies (15 papers), or their study cohort was smaller than 10 patients ( 25 papers). Six additional articles covering the study topic and meeting our inclusion criteria were found among the references of initially selected articles and thus were included. 
TABLE 1. Literature review of mMEP warning criteria focused on ST surgery

\begin{tabular}{|c|c|c|c|c|c|c|c|c|}
\hline $\begin{array}{l}\text { Authors } \\
\& \text { Year }\end{array}$ & Pathology & $\begin{array}{l}\text { No. of } \\
\text { Patients }\end{array}$ & mMEP Warning Criteria & $\begin{array}{l}\text { Other } \\
\text { IONM }\end{array}$ & Sensitivity & Specificity & PPV & NPV \\
\hline $\begin{array}{l}\text { Kothbauer et al., } \\
1998\end{array}$ & IMSCT & 100 & $\begin{array}{l}\text { Presence/absence of } \\
\text { response }\end{array}$ & $\begin{array}{l}\text { SSEP, D } \\
\text { wave }\end{array}$ & $100 \%$ & $91 \%$ & NA & NA \\
\hline $\begin{array}{l}\text { Quiñones-Hinojosa } \\
\text { et al., } 2005\end{array}$ & IMSCT & 28 & $\begin{array}{l}\text { Alterations in morphology } \\
\& \text { reduction in duration }\end{array}$ & SSEP & NA & NA & NA & NA \\
\hline Sala et al., 2006 & IMSCT & $\begin{array}{c}100(50 \mathrm{w} / \mathrm{IONM}+50 \\
\text { historical controls })\end{array}$ & $\begin{array}{l}\text { Presence/absence of } \\
\text { response }\end{array}$ & $\begin{array}{l}\text { SSEP, D } \\
\text { wave }\end{array}$ & NA & NA & NA & NA \\
\hline $\begin{array}{l}\text { Calancie \& Molano, } \\
2008\end{array}$ & $\begin{array}{l}\text { ST, tethered cord, ortho- } \\
\text { pedic, vascular cyst }\end{array}$ & $903(239 \mathrm{ST})$ & $\begin{array}{l}\text { Threshold increase (>100 } \\
\text { V) }\end{array}$ & NA & $100 \% *$ & $99.7 \%{ }^{*}$ & $97.8 \%{ }^{*}$ & $100 \% *$ \\
\hline $\begin{array}{l}\text { Krammer et al., } \\
2009\end{array}$ & ST & 31 & $\begin{array}{l}\text { Amplitude decrease } 50 \% \text {, } \\
\text { latency increase } 10 \% \text {, } \\
\text { threshold increase } 20 \%\end{array}$ & NA & $83 \%$ & $86 \%$ & $63 \%$ & $95 \%$ \\
\hline Hyun \& Rhim, 2009 & IMSCT & 17 & Amplitude decrease $50 \%$ & SSEP & $100 \%$ & $25 \%$ & NA & NA \\
\hline Forster et al., 2012 & ST & 203 & $\begin{array}{l}\text { Presence/absence of } \\
\text { response }\end{array}$ & $\begin{array}{c}\text { SSEP, D } \\
\text { wave }\end{array}$ & $95 \%$ & $98.9 \%$ & NA & NA \\
\hline $\begin{array}{l}\text { Kobayashi et al., } \\
2014\end{array}$ & ST, orthopedic & 959 (360 ST) & $\begin{array}{l}\text { Amplitude decrease } 70 \% \\
\quad \text { or more }\end{array}$ & NA & $95 \%{ }^{*}$ & $91 \%{ }^{*}$ & $33 \%{ }^{*}$ & $99 \% *$ \\
\hline Choi et al., 2014 & IMSCT & 50 & Amplitude decrease $75 \%$ & SSEP & $94 \%$ & $94 \%$ & $89 \%$ & $97 \%$ \\
\hline
\end{tabular}

Data were obtained from 28 papers that dealt with monitoring and 11 articles that dealt with mapping techniques.

\section{Monitoring Techniques}

Somatosensory Evoked Potentials

Somatosensory evoked potentials (SSEPs) provide monitoring of the dorsal column and medial lemniscus pathways that carry tactile discrimination, vibration, and joint and/or muscle sensation ${ }^{6,19,37}$ through stimulation of the median nerve at the wrist, the posterior tibial nerve at the ankle, and the pudendal nerve (intensity $40 \mathrm{~mA}$, duration $0.2 \mathrm{msec}$, repetition rate $4.3 \mathrm{~Hz}$ ) and through recording by corkscrew-like electrodes inserted in the scalp at $\mathrm{Cz} / \mathrm{Fz}$ (legs) and $\mathrm{C} 3 / \mathrm{C} 4 / \mathrm{Fz}$ (arms), according to the International 10-20 system of electrode placement. ${ }^{18,19}$ One of the most significant limitations of SSEPs is that they require averaging, which prolongs their acquisition time. Generally accepted SSEP warning criteria are a 50\% drop in amplitude and/or a $10 \%$ prolongation in latency. ${ }^{44} \mathrm{In}$ ST surgery, SSEP sensitivity is between $75 \%$ and $94 \%$, with specificity ranging from $50 \%$ to $100 \%$ in anticipating postoperative deficits..$^{16,21,47} \mathrm{In}$ this scenario, there is general agreement in the neurosurgical community to pause the surgical procedure or move toward a different route along the tumor while continuing the surgery as long as motor evoked potentials remain stable. ${ }^{42}$

\section{Motor Evoked Potentials}

\section{Muscle MEPs: Multipulse Technique.}

Muscle MEPs (mMEPs) are a reliable technique for monitoring motor pathways. ${ }^{41,44}$ Transcranial electrical stimulation with a multipulse technique is used for eliciting mMEPs and includes short trains of 5 square-wave stimuli (single pulse duration $0.5 \mathrm{msec}$, interstimulus in- terval $4 \mathrm{msec}$, rate $2 \mathrm{~Hz}$ ) through corkscrew electrodes placed at $\mathrm{C} 1 / \mathrm{C} 2$ (lower limbs) and $\mathrm{C} 3 / \mathrm{C} 4$ (upper limbs) scalp sites. The mMEPs are recorded through needle electrodes inserted into the upper- and lower-extremity muscles; they do not require averaging, but they do have wide amplitude and morphological variability ${ }^{30}$ In monitoring conus medullaris and cauda equina motor integrity during ST surgery, mMEPs are the most reliable method. Different warning criteria for mMEPs during ST surgery have been proposed: presence or absence of responses, ${ }^{16,22,26,28,44}$ changes in thresholds,, 5 changes in waveform,${ }^{40}$ or amplitude variations, $7,21,24,29,33,34$ with the first listed criterion being the most effective. In ST surgery, mMEP sensitivity in anticipating postoperative motor deficits ranges from $75 \%$ to $100 \%$, with a specificity from $25 \%$ to $100 \%$, a positive predictive value (PPV) ranging from $63 \%$ to $100 \%$, and a negative predictive value (NPV) ranging from $75 \%$ to $97 \%$ (Table 1). $.16,21,28,29,47$ In conus medullaris and cauda equina tumor surgery, it is imperative to maintain and preserve MEPs; any loss may indicate a complete lower motor neuron lesion, anticipating a postoperative motor deficit with little tendency to recover. ${ }^{27}$ In case of an alert, surgeons should pause the procedure and irrigate with warm saline solution and papaverine while the anesthesiologist increases blood pressure. ${ }^{42}$

Direct Wave: A Single-Pulse Technique.

The direct (D) wave is a direct measure of the number of functioning fast-conducting fibers in the corticospinal tract (CST). ${ }^{30}$ As fibers numerically decrease craniocaudally and are absent in the lumbosacral region, the use of $\mathrm{D}$ waves is limited in the cord up to T10-11. The D wave is elicited by a single-pulse stimulating technique $(0.5 \mathrm{msec}$ duration) and are recorded from the epidural or subdural spaces of the SC. ${ }^{9}$ In contrast to mMEPs and SSEPs, the $\mathrm{D}$ wave is not influenced by blood pressure, heart rate, 
temperature, and anesthesia drugs, but it needs midline recording. ${ }^{8} \mathrm{~A}$ warning criterion is a decrease of more than $50 \%$ of the baseline amplitude. ${ }^{8,42}$ Although D-wave monitoring is actually considered the gold standard ${ }^{8,42}$ for assessing the integrity of the CST in spinal monitoring, no study in the literature has specifically addressed the issue of D-wave accuracy in ST surgery.

\section{Free-Running (Spontaneous) Electromyography}

Free-running electromyography (frEMG) intraoperatively monitors NRs ${ }^{19}$ with spontaneous activity recorded via needle electrodes placed in the muscles of interest. Relevant frEMG activity includes spikes, bursts, or trains ${ }^{19}$ and the occurrence of neurotonic discharges during IONM may anticipate nerve injury. In the literature, only the report by Skinner et al. ${ }^{47}$ specifically addresses the role of frEMG in detecting early motor tract injury during ST surgery. Warning criteria were 1) irregular aperiodic bursts repeatedly elicited by surgical maneuvers within the tumor bed; 2 ) prolonged ( $>3 \mathrm{sec}$ ), focal, semirhythmical tonic discharges; and 3) an acute drop in signal in one or more limbs. Free-running EMG sensitivity and specificity were $87.5 \%$ and $83.3 \%$, respectively; its PPV was $87.5 \%$ and NPV was $83.3 \%$.

\section{Bulbocavernosus Reflex}

The bulbocavernosus reflex (BCR) is the most useful intraoperative tool for monitoring sphincter function in real time. The dorsal penile or clitoral nerves are stimulated with 2 surface electrodes, and recordings are obtained from the external anal sphincter muscle via wire or needle electrodes. To elicit the BCR, a short train of 5 stimuli is used. ${ }^{27}$ No alert criteria exist for the intraoperative BCR, with the disappearance of the response considered an alarm, especially when occurring in surgery with a consistent risk of postoperative sphincter dysfunction. ${ }^{48}$ However, intraoperative BCR data and their correlation with long-term sphincter control, sphincter-detrusor dyssynergia, and sexual function, especially in ST surgery, need further investigation. ${ }^{27}$

\section{Mapping Techniques \\ Dorsal Column Mapping}

Dorsal column mapping (DCM), a tool described in a limited number of reports, $35,38,46,52$ is a useful technique for intraoperative midline localization during posterior myelotomy, to avoid the "dorsal column dysfunction" syndrome (numbness, painful dysesthesias below the surgical level, proprioceptive loss, and gait dysfunction). Three main techniques have been described: 1) In 2002, Quiñones-Hinojosa et al..$^{38}$ described 2 patients in whom antidromically elicited SSEPs were evoked by stimulation of the dorsal column and were recorded with subdermal electrodes placed at the medial malleolus bilaterally. 2) In 2010, in a group of 10 patients with intramedullary spinal cord tumor (IMSCT), Yanni et al. ${ }^{52}$ described the registration of SSEPs from a miniature microelectrode grid (made up of 8 parallel Teflon-coated stainless steel wires) placed over the posterior SC surface after stimulation of both tibial nerves at the ankle (stimulus intensity $40 \mathrm{~mA}$, duration $0.2 \mathrm{msec}$, rate $13.3 \mathrm{~Hz}$ ). 3) In 2012, Simon et al. ${ }^{46}$ published a case report describing the use of the "gracilis tract SSEPs phase-reversal technique" consisting of SSEP recording through scalp electrodes after direct electrical stimulation using an 8-contact mini-electrode strip placed on the dorsal SC. In 2012, Mehta et al. ${ }^{32}$ described the use of DCM during surgery in 11 patients with IMSCT, comparing their outcomes with those of a control group of 80 patients. These authors found a decreased rate of postoperative posterior column dysfunction using intraoperative DCM.

\section{Intramedullary Motor Mapping}

A few reports in the literature focus on techniques useful for real-time identification of the anatomical site of the CST within the SC. ${ }^{10,12,13,17,38}$ Duffau et al., ${ }^{13}$ in 1998, described the use of a modified bipolar probe $(4 \mathrm{~mm}$ distance of stimulating surfaces) for direct medullary electrical stimulations $(60 \mathrm{~Hz}$, biphasic square-wave pulses with $1 \mathrm{msec} / \mathrm{phase}, 0.9 \mathrm{~mA}$ ) during surgery in 3 patients with IMSCT. These authors concluded that direct medullary electrical stimulation is a safe, easy, precise, and reliable method of reducing morbidity during SC surgery. In 2001, Deletis et al. ${ }^{10}$ described the "D-wave collision technique," obtained by simultaneous stimulation of the SC and transcranial electrical stimulation. As the resulting signals are transmitted along the same axons, the descending D wave collides with the ascending signal carried antidromically along the CST. It results in a decrease in the D-wave amplitude caudally to the collision site. Even in the early stages of its development, this methodology has proven to be highly successful in identifying and localizing the CST within the SC. ${ }^{11}$ In 2002, Quiñones-Hinojosa et al..$^{38}$ described the resection of 2 IMSCTs using the Ojemann cortical stimulator (model OCS-1 with stimulating tips 5 $\mathrm{mm}$ apart). Stimulation of abnormal tissue within the tumor did not elicit electromyographic activity. These authors concluded that mapping SC motor tracts with direct SC stimulation and electromyographic recording facilitated a more extensive resection. In 2015, Gandhi et al. ${ }^{17}$ described the use of intraoperative motor fiber tract stimulation to map the CST associated with a cervicomedullary junction cystic ependymoma. High-resolution motor mapping was performed using a Kartush concentric bipolar stimulating probe (overall width of $2 \mathrm{~mm}$ ) with a biphasic waveform (repetition rate $60.11 \mathrm{~Hz}$, pulse width $1.0 \mathrm{msec}$, stimulation intensities ranging from 0.1 to $1.0 \mathrm{~mA}$ ) with registrations on individual muscle groups. They stated that high-resolution mapping of the SC motor pathways by using direct fiber stimulation may improve the safety of IMSCT surgery.

\section{Triggered EMG: Direct Nerve Stimulation}

Intraoperative identification of motor NRs is accomplished by direct electrical handheld monopolar or bipolar forceps stimulation. ${ }^{27}$ Recording from the target muscles reveals the EMG responses supplied by the stimulated NR. In the literature, a limited number of reports describe the intraoperative use of direct nerve stimulation (DNS). ${ }^{20,23}$ In 2006, Guo et al. ${ }^{20}$ described triggered EMG during surgery in 10 intraspinal cervical dumbbell and foraminal tumors; DNS and recording of compound muscle 
TABLE 2. Review focused on IONM accuracy in ST surgery

\begin{tabular}{|c|c|c|c|c|c|c|}
\hline Authors \& Year & No. of Patients (pathology) & IONM Techniques & Sensitivity & Specificity & PPV & NPV \\
\hline Kothbauer et al., 1998 & 100 (IMSCT) & SSEP, MEP, D wave & $\begin{array}{c}\text { MEP+D wave } 100 \\
\% \text {, SSEP NA }\end{array}$ & $\begin{array}{l}\text { MEP+D wave } \\
91 \%, \text { SSEP NA }\end{array}$ & NA & NA \\
\hline Skinner et al., 2005 & 14 (IMSCT) & SSEP, MEP, frEMG & mIONM 100\% & mIONM 83\% & mIONM 89\% & mIONM $100 \%$ \\
\hline Sala et al., 2006 & $\begin{array}{c}100 \text { (IMSCT } 50 \mathrm{w} / \text { IONM + } \\
50 \text { historical controls) }\end{array}$ & SSEP, MEP, D wave & NA & NA & NA & NA \\
\hline Sutter et al., 2007 & $\begin{array}{l}109 \text { (45 EXDST, } 41 \\
\text { IDEMSCT, } 23 \text { IMSCT) }\end{array}$ & $\begin{array}{c}\text { cm-EP, cs-EP, ns-EP, } \\
\text { nc-EP, sm-EP, ss- } \\
\text { EP, BCR, BAR }\end{array}$ & mIONM 92\% & mIONM 99\% & mIONM 96\% & mIONM 98\% \\
\hline Sandalcioglu et al., 2008 & 131 (IDEMSCT) & SSEP & NA & NA & NA & NA \\
\hline Krammer et al., 2009 & $\begin{array}{l}31 \text { (13 IMSCT, } 14 \\
\text { IDEMSCT, } 3 \text { EXDST, } 1 \\
\text { other) }\end{array}$ & MEP & MEP $83 \%$ & MEP $86 \%$ & MEP $63 \%$ & MEP $95 \%$ \\
\hline Hyun et al., 2009 & 17 (IMSCT) & SSEP, MEP & mIONM 100\% & mIONM 28\% & NA & NA \\
\hline Forster et al., 2012 & $\begin{array}{l}203 \text { (50 IMSCT, } 141 \\
\text { IDEMSCT+EXDST, } 12 \\
\text { other) }\end{array}$ & SSEP, MEP, D wave & $\begin{array}{l}\text { MEP 95\%, SSEP } \\
94 \% \text {, D wave } \\
\text { NA }\end{array}$ & $\begin{array}{l}\text { MEP } 98,9 \% \\
\text { SSEP } 97 \% \text {, D } \\
\text { wave NA }\end{array}$ & NA & NA \\
\hline Choi et al., 2014 & $50(\mathrm{IMSCT})$ & SSEP, MEP & $\begin{array}{l}\text { MEP } 94 \%, \text { SSEP } \\
\text { NA }\end{array}$ & $\begin{array}{l}\text { MEP } 94 \%, \text { SSEP } \\
\text { NA }\end{array}$ & $\begin{array}{l}\text { MEP } 89 \%, \\
\text { SSEP NA }\end{array}$ & $\begin{array}{l}\text { MEP } 97 \%, \\
\text { SSEP NA }\end{array}$ \\
\hline Avila et al., 2013 & 152 (EXDST) & SSEP, MEP, EMG & NA & $\begin{array}{r}\text { SSEP } 95 \%, \text { MEP } \\
97 \%, \text { EMG NA }\end{array}$ & NA & NA \\
\hline Ghadirpour et al., 2015 & 68 (IDEMSCT) & SSEP, MEP, D wave & NA & NA & NA & NA \\
\hline Korn et al., 2015 & 100 (IDEMSCT) & $\begin{array}{l}\text { SSEP, MEP, D wave, } \\
\text { EMG }\end{array}$ & mIONM 82\% & mIONM 95\% & mlONM 82\% & mIONM 95\% \\
\hline
\end{tabular}

$\mathrm{BAR}=$ bulbo-anal reflex; $\mathrm{cm}-\mathrm{EP}=$ cerebromuscular evoked potential; $\mathrm{cs}-\mathrm{EP}=$ cerebrospinal evoked potential; $\mathrm{nc}-\mathrm{EP}=$ neurocerebral evoked potential; $\mathrm{ns}-\mathrm{EP}=$ neurospinal evoked potential; sm-EP = spinomuscular evoked potential; ss-EP = spinospinal evoked potential.

action potentials facilitated NR identification, anticipating the postoperative function. These authors concluded that DNS may also be useful in predicting postoperative outcome when NR sacrifice is necessary, despite the absence of an intraoperative motor response. Similar conclusions were provided by Kaneko et al. ${ }^{23}$ in 2006, in their series of 5 cervical schwannomas.

\section{Multimodal IONM}

The accuracy of IONM is increased when multiple tools are simultaneously employed., ${ }^{2,49}$ Few studies have specifically addressed the value of multimodal IONM (mIONM) in ST surgery (Table 2). In 2007, Sutter et al. ${ }^{50}$ published a prospective series of 109 patients demonstrating a sensitivity and specificity of $92 \%$ and $99 \%$, respectively, with a PPV of $96 \%$ and NPV of $98 \%$. These authors concluded that mIONM is an effective method of monitoring SC and NR function in ST surgery and can reduce or even prevent the occurrence of postoperative neurological deficit. In 2010, Malhotra and Shaffrey, ${ }^{31}$ in a large retrospective systematic review of 187 publications, concluded that mIONM may be useful in preserving neurological function where modifications of the surgical approach are possible. In 2009, Hyun and Rhim ${ }^{21}$ described the combined use of mMEPs and SSEPs during surgery on 17 IMSCTs. They reported a sensitivity of $100 \%$ and a specificity of $83 \%$, concluding that combined SSEP and mMEP monitoring provided higher sensitivity and higher PPV and NPV than a single-modality technique. In 2015, Korn et al. ${ }^{25}$ assessed the use of mIONM during surgery on 100 patients with intradural-extramedullary SC tumors (IDEMSCTs). In their series, mIONM demonstrated a sensitivity, specificity, PPV, and NPV of $82 \%, 95 \%, 82 \%$, and $95 \%$, respectively, allowing the authors to conclude that $\mathrm{mIONM}$ is useful in the context of IDEMSCTs for identifying iatrogenic injury to the SC.

\section{Discussion}

Spinal tumor surgery carries the risk of new neurological deficits in the postoperative period. Despite consensus in the neurosurgical community favoring the use of IONM in ST surgery, there is still a need for a definite strategy to routinely and safely monitor the SC and NRs intraoperatively, assisting in diagnosis and anticipating the occurrence of postoperative neurological injury. ${ }^{1}$

In the present study we addressed the rationale for and the accuracy (in terms of sensitivity, specificity, PPV, and NPV) of IONM in ST surgery in light of more recent evidence in the pertinent literature. ${ }^{15,36}$ Although there are numerous validated techniques that can map and monitor different SC and NR functions, each method alone cannot significantly reduce the incidence of neurological injury or mitigate its severity. ${ }^{1}$ Conversely, the accuracy of IONM is increased when multiple tools are simultaneously employed, reaching a sensitivity, specificity, PPV, and NPV as high as $100 \%, 99 \%, 96 \%$, and $100 \%$, respectively. ${ }^{21,25,47,50}$ Although few studies have specifically addressed the value of mIONM in ST surgery, the results are important for an oncological cure while ensuring patient safety and considering medicolegal aspects. 
The first regular attempt to intraoperatively check for SC and NR function was made in the 1970s by introducing the "wake up" test. ${ }^{51}$ Although the use of this test decreased the incidence of postoperative neurological deficits, it did not allow for the continuous monitoring of SC and NR function. Nowadays, despite the wide use of IONM in complex spinal surgeries, there is still ongoing debate on what is considered an indispensable tool. In 2012, Nuwer et al., ${ }^{36}$ on behalf of the American Academy of Neurology, evaluated 40 studies dealing with IONM during spine surgery. They restricted their analysis to 4 Class I and 8 Class II studies with an evidence-based approach, providing evidence that persistent changes in IONM correlated with the occurrence of new neurological deficits in the postoperative period. The authors concluded that IONM is effective in predicting an increased risk of postoperative neurological deficits and that the specialists and other participants of an operative team should be notified about the increased risk of adverse neurological events in patients with significant IONM changes (level A). In 2010, similar results were described by Fehlings et al. ${ }^{15}$ in a systematic review of 103 papers; they found a high level of evidence that mIONM is accurate for anticipating neurological sequelae in spine surgery, a low level of evidence that mIONM decreases the occurrence of new or worsened perioperative neurological deficits, and a very low level of evidence that an intraoperative response to neuromonitoring warnings reduces the rate of perioperative neurological deterioration. In their conclusions, the authors recommended the use of mIONM in spine surgery in which the SC or NRs are deemed to be at risk. In 2006, Sala et al. ${ }^{44}$ quantified the real impact of mIONM (SSEP, mMEP, and D wave) in intramedullary ST surgery by comparing the neurological outcome of 50 patients with those of a historical control group of equal size. The authors reported that the level of evidence for the use of IONM in IMSCT surgery remained confined to Class II and III studies as a prospective randomized study was unacceptable for ethical and medicolegal reasons. They concluded that a combined mMEP and $\mathrm{D}$-wave protocol significantly improved motor outcome at 3 months. While different studies in the literature highlight the value of IONM during IMSCT surgery (Table 2), ${ }^{21,28,44,47}$ its routine use during IDEMSCT and extradural ST (EXDST) surgery is still under debate. ${ }^{3,14,18}$ Among the studies specifically addressing the outcome of patients undergoing surgery for IDEMSCT with IONM, Ghadirpour et al., 18 in 2015, described a series of 68 patients who underwent mIONM (SSEP, mMEP, and D wave); significant IONM changes occurred in $7.35 \%$ of patients, inducing a modification of the surgical strategy that was able to prevent and mitigate postoperative neurological sequelae. As IONM predicted a good neurological outcome in $92.65 \%$ of their patients, these authors concluded that IONM allowed for safer tumor removal. Also in 2015, Korn et al. ${ }^{25}$ examined IONM results in 100 patients with IDEMSCT. Multimodal IONM demonstrated a high level of accuracy, with sensitivity and specificity as high as $82 \%$ and $95 \%$, respectively, PPV of $82 \%$, and NPV of $95 \%$. These authors concluded that IONM is feasible and useful in the treatment of IDEMSCTs, particularly in identifying injury to the SC. Conversely, in a series of 131 spinal meningiomas operated on with SSEPs, Sandalcioglu et al..$^{45}$ reported an improved or unchanged neurological status in $96.2 \%$ of patients and a worsened status in 3\%; the authors concluded that good clinical outcomes could be reached without the use of sophisticated monitoring. In a different ST scenario, that is, EXDSTs, the utility of IONM was the focus of Avila et al. ${ }^{3}$ in 2013. They evaluated 152 patients undergoing decompression for EXDST compression with mIONM (SSEP, mMEP, and EMG), concluding that this combination increased the accuracy of monitoring and was important given the risk of SC injury due to instrumentation and resection of tumor causing SC compression.

Different inferences should be made regarding mapping techniques. Mapping of neural structures during ST surgery could be considered a well-established method for spinal NR lesions ${ }^{27}$ On the other hand, mapping techniques of motor and sensory functions of the SC are a relatively new application; therefore, the number of patients evaluated is still limited. Nevertheless, although it is difficult to draw definitive conclusions, current data suggest that these techniques may be useful tools to minimize postoperative motor and sensory dysfunction. . $^{10,11,39,52}$

\section{Conclusions}

This review confirms the role of mIONM as an essential tool in the operative workup for ST surgery. Single monitoring procedures are clearly not sufficient to account for the complex function of the SC and NRs. On the other hand, mIONM is highly sensitive and specific for anticipating neurological injury during ST surgery and represents an important tool in preserving neuronal structures and achieving an optimal postoperative functional outcome.

\section{References}

1. AANS/CNS Joint Section on the Disorders of the Spine and Peripheral Nerves: Updated Position Statement: Intraoperative Electrophysiological Monitoring, April 2014. (http://www.spinesection.org/files/pdfs/IOM\%20Position\%20 Statement\%2004.24.2014.pdf) [Accessed June 21, 2016]

2. Ando M, Tamaki T, Yoshida M, Kawakami M, Kubota S, Nakagawa Y, et al: Intraoperative spinal cord monitoring using combined motor and sensory evoked potentials recorded from the spinal cord during surgery for intramedullary spinal cord tumor. Clin Neurol Neurosurg 133:18-23, 2015

3. Avila EK, Elder JB, Singh P, Chen X, Bilsky MH: Intraoperative neurophysiologic monitoring and neurologic outcomes in patients with epidural spine tumors. Clin Neurol Neurosurg 115:2147-2152, 2013

4. Calancie B, Harris W, Broton JG, Alexeeva N, Green BA: "Threshold-level" multipulse transcranial electrical stimulation of motor cortex for intraoperative monitoring of spinal motor tracts: description of method and comparison to somatosensory evoked potential monitoring. J Neurosurg 88:457-470, 1998

5. Calancie B, Molano MR: Alarm criteria for motor-evoked potentials: what's wrong with the "presence-or-absence" approach? Spine (Phila Pa 1976) 33:406-414, 2008

6. Chiappa K, Hill R: Short latency somatosensory evoked potentials: methodology, in Chiappa K (ed): Evoked Potentials in Clinical Medicine. Philadelphia: Lippincott-Raven, 1997

7. Choi I, Hyun SJ, Kang JK, Rhim SC: Combined muscle motor and somatosensory evoked potentials for intramedullary 
spinal cord tumour surgery. Yonsei Med J 55:1063-1071, 2014

8. Costa P, Peretta P, Faccani G: Relevance of intraoperative D wave in spine and spinal cord surgeries. Eur Spine J 22:840-848, 2013

9. Deletis V: Intraoperative monitoring of the functional integrity of the motor pathways. Adv Neurol 63:201-214, 1993

10. Deletis V, Bueno De Camargo A: Interventional neurophysiological mapping during spinal cord procedures. Stereotact Funct Neurosurg 77:25-28, 2001

11. Deletis V, Sala F: Intraoperative neurophysiological monitoring of the spinal cord during spinal cord and spine surgery: a review focus on the corticospinal tracts. Clin Neurophysiol 119:248-264, 2008

12. Deletis V, Sala F: The role of intraoperative neurophysiology in the protection or documentation of surgically induced injury to the spinal cord. Ann N Y Acad Sci 939:137-144, 2001

13. Duffau H, Capelle L, Sichez J: Direct spinal cord electrical stimulations during surgery of intramedullary tumoral and vascular lesions. Stereotact Funct Neurosurg 71:180-189, 1998

14. Eleraky MA, Setzer M, Papanastassiou ID, Baaj AA, Tran ND, Katsares KM, et al: Role of motor-evoked potential monitoring in conjunction with temporary clipping of spinal nerve roots in posterior thoracic spine tumor surgery. Spine $\mathbf{J}$ 10:396-403, 2010

15. Fehlings MG, Brodke DS, Norvell DC, Dettori JR: The evidence for intraoperative neurophysiological monitoring in spine surgery: does it make a difference? Spine (Phila Pa 1976) 35 (9 Suppl):S37-S46, 2010

16. Forster MT, Marquardt G, Seifert V, Szelényi A: Spinal cord tumor surgery-importance of continuous intraoperative neurophysiological monitoring after tumor resection. Spine (Phila Pa 1976) 37:E1001-E1008, 2012

17. Gandhi R, Curtis CM, Cohen-Gadol AA: High-resolution direct microstimulation mapping of spinal cord motor pathways during resection of an intramedullary tumor. J Neurosurg Spine 22:205-210, 2015

18. Ghadirpour R, Nasi D, Iaccarino C, Giraldi D, Sabadini R, Motti L, et al: Intraoperative neurophysiological monitoring for intradural extramedullary tumors: why not? Clin Neurol Neurosurg 130:140-149, 2015

19. Gonzalez AA, Jeyanandarajan D, Hansen C, Zada G, Hsieh PC: Intraoperative neurophysiological monitoring during spine surgery: a review. Neurosurg Focus 27(4):E6, 2009

20. Guo L, Quiñones-Hinojosa A, Yingling CD, Weinstein PR: Continuous EMG recordings and intraoperative electrical stimulation for identification and protection of cervical nerve roots during foraminal tumor surgery. J Spinal Disord Tech 19:37-42, 2006

21. Hyun SJ, Rhim SC: Combined motor and somatosensory evoked potential monitoring for intramedullary spinal cord tumor surgery: correlation of clinical and neurophysiological data in 17 consecutive procedures. Br J Neurosurg 23:393400, 2009

22. Jin SH, Chung CK, Kim CH, Choi YD, Kwak G, Kim BE: Multimodal intraoperative monitoring during intramedullary spinal cord tumor surgery. Acta Neurochir (Wien) 157:2149-2155, 2015

23. Kaneko K, Kato Y, Kojima T, Imajyo Y, Taguchi T: Intraoperative electrophysiologic studies on the functions of nerve roots involved in cervical dumbbell-shaped schwannoma and their clinical utility. J Spinal Disord Tech 19:571-576, 2006

24. Kobayashi S, Matsuyama Y, Shinomiya K, Kawabata S, Ando M, Kanchiku T, et al: A new alarm point of transcranial electrical stimulation motor evoked potentials for intraoperative spinal cord monitoring: a prospective multicenter study from the Spinal Cord Monitoring Working Group of the Japanese
Society for Spine Surgery and Related Research. J Neurosurg Spine 20:102-107, 2014

25. Korn A, Halevi D, Lidar Z, Biron T, Ekstein P, Constantini S: Intraoperative neurophysiological monitoring during resection of intradural extramedullary spinal cord tumors: experience with 100 cases. Acta Neurochir (Wien) 157:819-830, 2015

26. Kothbauer KF: Intraoperative neurophysiologic monitoring for intramedullary spinal-cord tumor surgery. Neurophysiol Clin 37:407-414, 2007

27. Kothbauer KF, Deletis V: Intraoperative neurophysiology of the conus medullaris and cauda equina. Childs Nerv Syst 26:247-253, 2010

28. Kothbauer KF, Deletis V, Epstein FJ: Motor-evoked potential monitoring for intramedullary spinal cord tumor surgery: correlation of clinical and neurophysiological data in a series of 100 consecutive procedures. Neurosurg Focus 4(5):e1, 1998

29. Krammer MJ, Wolf S, Schul DB, Gerstner W, Lumenta CB: Significance of intraoperative motor function monitoring using transcranial electrical motor evoked potentials (MEP) in patients with spinal and cranial lesions near the motor pathways. Br J Neurosurg 23:48-55, 2009

30. Macdonald DB, Skinner S, Shils J, Yingling C: Intraoperative motor evoked potential monitoring-a position statement by the American Society of Neurophysiological Monitoring. Clin Neurophysiol 124:2291-2316, 2013

31. Malhotra NR, Shaffrey CI: Intraoperative electrophysiological monitoring in spine surgery. Spine (Phila Pa 1976) 35:2167-2179, 2010

32. Mehta AI, Mohrhaus CA, Husain AM, Karikari IO, Hughes B, Hodges T, et al: Dorsal column mapping for intramedullary spinal cord tumor resection decreases dorsal column dysfunction. J Spinal Disord Tech 25:205-209, 2012

33. Morota N, Deletis V, Constantini S, Kofler M, Cohen H, Epstein FJ: The role of motor evoked potentials during surgery for intramedullary spinal cord tumors. Neurosurgery 41:1327-1336, 1997

34. Muramoto A, Imagama S, Ito Z, Ando K, Tauchi R, Matsumoto T, et al: The cutoff amplitude of transcranial motor evoked potentials for transient postoperative motor deficits in intramedullary spinal cord tumor surgery. Spine (Phila Pa 1976) 39:E1086-E1094, 2014

35. Nair D, Kumaraswamy VM, Braver D, Kilbride RD, Borges LF, Simon MV: Dorsal column mapping via phase reversal method: the refined technique and clinical applications. Neurosurgery 74:437-446, 2014

36. Nuwer MR, Emerson RG, Galloway G, Legatt AD, Lopez J, Minahan R, et al: Evidence-based guideline update: intraoperative spinal monitoring with somatosensory and transcranial electrical motor evoked potentials. J Clin Neurophysiol 29:101-108, 2012

37. Prestor B, Golob P: Intra-operative spinal cord neuromonitoring in patients operated on for intramedullary tumors and syringomyelia. Neurol Res 21:125-129, 1999

38. Quinones-Hinojosa A, Gulati M, Lyon R, Gupta N, Yingling C: Spinal cord mapping as an adjunct for resection of intramedullary tumors: surgical technique with case illustrations. Neurosurgery 51:1199-1207, 2002

39. Quiñones-Hinojosa A, Lyon R, Ames CP, Parsa AT: Neuromonitoring during surgery for metastatic tumors to the spine: intraoperative interpretation and management strategies. Neurosurg Clin N Am 15:537-547, 2004

40. Quiñones-Hinojosa A, Lyon R, Zada G, Lamborn KR, Gupta $\mathrm{N}$, Parsa AT, et al: Changes in transcranial motor evoked potentials during intramedullary spinal cord tumor resection correlate with postoperative motor function. Neurosurgery 56:982-993, 2005

41. Rajshekhar V, Velayutham P, Joseph M, Babu KS: Factors 
predicting the feasibility of monitoring lower-limb muscle motor evoked potentials in patients undergoing excision of spinal cord tumors. J Neurosurg Spine 14:748-753, 2011

42. Sala F, Bricolo A, Faccioli F, Lanteri P, Gerosa M: Surgery for intramedullary spinal cord tumors: the role of intraoperative (neurophysiological) monitoring. Eur Spine J 16 (Suppl 2):S130-S139, 2007

43. Sala F, Dvorak J, Faccioli F: Cost effectiveness of multimodal intraoperative monitoring during spine surgery. Eur Spine J 16 (Suppl 2):S229-S231, 2007

44. Sala F, Palandri G, Basso E, Lanteri P, Deletis V, Faccioli F, et al: Motor evoked potential monitoring improves outcome after surgery for intramedullary spinal cord tumors: a historical control study. Neurosurgery 58:1129-1143, 2006

45. Sandalcioglu IE, Hunold A, Müller O, Bassiouni H, Stolke D, Asgari S: Spinal meningiomas: critical review of 131 surgically treated patients. Eur Spine J 17:1035-1041, 2008

46. Simon MV, Chiappa KH, Borges LF: Phase reversal of somatosensory evoked potentials triggered by gracilis tract stimulation: case report of a new technique for neurophysiologic dorsal column mapping. Neurosurgery 70:E783-E788, 2012

47. Skinner SA, Nagib M, Bergman TA, Maxwell RE, Msangi $\mathrm{G}$ : The initial use of free-running electromyography to detect early motor tract injury during resection of intramedullary spinal cord lesions. Neurosurgery 56 (2 Suppl):299-314, 2005

48. Skinner SA, Vodušek DB: Intraoperative recording of the bulbocavernosus reflex. J Clin Neurophysiol 31:313-322, 2014

49. Sutter M, Eggspuehler A, Grob D, Jeszenszky D, Benini A, Porchet F, et al: The diagnostic value of multimodal intraoperative monitoring (MIOM) during spine surgery: a prospective study of 1,017 patients. Eur Spine J 16 (Suppl 2):S162S170, 2007

50. Sutter M, Eggspuehler A, Grob D, Jeszenszky D, Benini A,
Porchet F, et al: The validity of multimodal intraoperative monitoring (MIOM) in surgery of 109 spine and spinal cord tumors. Eur Spine J 16 (Suppl 2):S197-S208, 2007

51. Vauzelle C, Stagnara P, Jouvinroux P: Functional monitoring of spinal cord activity during spinal surgery. Clin Orthop Relat Res (93):173-178, 1973

52. Yanni DS, Ulkatan S, Deletis V, Barrenechea IJ, Sen C, Perin NI: Utility of neurophysiological monitoring using dorsal column mapping in intramedullary spinal cord surgery. J Neurosurg Spine 12:623-628, 2010

\section{Disclosures}

The authors report no conflict of interest concerning the materials or methods used in this study or the findings specified in this paper.

\section{Author Contributions}

Conception and design: all authors. Acquisition of data: Scibilia, Terranova, Morelli, Esposito. Analysis and interpretation of data: Raffa, Scibilia, Esposito, Germanò. Drafting the article: Raffa, Scibilia, Rizzo, Esposito, Germanò. Critically revising the article: Raffa, Scibilia, Terranova, Esposito, Conti, Quartarone, Germanò Reviewed submitted version of manuscript: all authors. Approved the final version of the manuscript on behalf of all authors: Raffa. Statistical analysis: Raffa. Administrative/technical/material support: Mallamace. Study supervision: Raffa, Scibilia, Terranova, Conti, Quartarone, Germanò.

\section{Correspondence}

Giovanni Raffa, Division of Neurosurgery, AOU Policlinico G. Martino, Via Consolare Valeria, 1, Messina 98125, Italy. email: mark83g@alice.it. 